\title{
REVIEW \\ PENERAPAN REGULASI ICH Q3D DAN PENGARUHNYA BAGI INDUSTRI FARMASI INDONESIA
}

\author{
Steven A. Pamolango ${ }^{1}$, Ida Musfiroh ${ }^{1)}$ \\ ${ }^{1)}$ Program Studi Profesi Apoteker \\ Fakultas Farmasi, Universitas Padjadjaran \\ Jalan Raya Bandung - Sumedang Km. 21 Jatinangor 45363 \\ Email : stevenpamolango@gmail.com
}

\begin{abstract}
Regulation issued by the International Council for Harmonization (ICH) in ICH Q3D makes the pharmaceutical industry need to consider the assessment of the impurity factors on the drug products they produce. The elemental impurity assessments have been based only on the heavy metal test, but ICH Q3D assessments requires specific method for each elemental impurity. To quantify the amount of the elemental impurities require a special instrument, The United State Pharmacopeia (USP) suggests the use of Inductively Coupled Plasma (ICP) as instrument in its tests. Indonesia National Agency of Drug and Food Control as the regulatory agency has not issued a special regulation related to the elemental impurities but some pharmaceutical companies in Indonesia who export their products to ICH member countries have conducted the risk assessment of elemental impurities especially the pharmaceutical companies with Foreign Investment.
\end{abstract}

Keywords : ICH Q3D, Elemental Impurities, Analysis Method, Risk Assessment.

\begin{abstract}
ABSTRAK
Peraturan yang dikeluarkan The International Council for Harmonisation (ICH) dalam ICH Q3D membuat industri farmasi perlu menerapkan penilaian resiko terhadap unsur pengotor pada produk obat yang mereka produksi. Sebelumnya, penilaian unsur pengotor selama ini hanya berdasarkan pengujian terhadap logam berat namun ICH Q3D mewajibkan pengujian spesifik untuk tiap unsur pengotor. Upaya untuk mengetahui unsur pengotor yang merupakan unsur logam memerlukan instrument khusus, dan pada United State Pharmacopeia (USP) menyarankan penggunaan Inductively coupled plasma (ICP) sebagai instrumen dalam pengujiannya. Badan Pengawas Obat dan Makanan Republik Indonesia sebagai instansi regulatory saat ini belum mengeluarkan regulasi khusus terkait unsur pengotor namun beberapa perusahaan farmasi di Indonesia yang melakukan proses ekspor produknya ke negara anggota ICH telah melakukan kajian resiko unsur pengotor terutama perusahaan farmasi dengan Penanaman Modal Asing (PMA).
\end{abstract}

Kata Kunci : ICH Q3D, Unsur Pengotor, Metode Analisis. Kajian Resiko. 


\section{PENDAHULUAN}

Pengotor dalam produk obat merupakan unsur asing yang bukan zat aktif maupun eksipien dari obat tersebut. Unsur tersebut tidaklah memiliki manfaat terapetik bagi pengguna obat bahkan memungkinkan untuk memberikan dampak negatif terhadap penggunanya dalam aspek keamanan. Keberadaan unsur pengotor memiliki potensi yang tinggi berkaitan dengan reaktifitas dan tingkat kemanan terhadap komposisi produk obat baik organik maupun tidak organik sehingga perlu diatur agar keberadaannya diketahui dan dapat dikontrol tetap rendah (Jenke, et al. 2015).

Umumnya produsen farmasi saat ini menunjukkan bahwa mereka memenuhi batas compendial pada zat obat dan eksipien dengan menerapkan uji logam berat farmakope berbasis pada presipitasi sulfida seperti prosedur yang dijelaskan dalam United State Pharmacopeia (USP) General Chapter <231> Heavy Metal (Li, $\mathrm{G}$, et al., 2015). Dengan adanya aturan pada ICH Q3D, kriteria penerimaan untuk bahan pengotor diganti dengan pengujian terhadap unsur spesifik sesuai dengan Permitted Daily Exposure (PDE).

ICH Q3D dibuat dengan tujuan untuk mengontrol kandungan pengotor di dalam produk farmasi yang dapat timbul dari berbagai faktor, bisa melalui residu katalist yang sengaja ditambahkan dalam proses pembuatan atau dapat timbul melalui interaksi dengan peralatan pembuatan produk farmasi itu sendiri. Karena kandungan pengotor ini tidak memberikan efek terapi yang bermanfaat terhadap pasien maka kandungan pengotor ini perlu untuk dikontrol jumlahnya dengan memperhatikan batas yang diperbolehkan (FDA, 2015).

Dengan adanya penerapan ICH Q3D di Amerika Serikat, Eropa, dan Jepang maka semua produk obat yang akan diekspor ke negara - negara tersebut harus memenuhi persyaratan dari ICH Q3D begitu juga dengan negara - negara yang menjadi pemantau ICH dan menerapkannya. Indonesia sebagai salah satu negara observer di ICH, pada masa mendatang dapat saja menerapkan aturan ini terlebih lagi bagi industri farmasi yang akan melakukan ekspor ke negara - negara ICH perlu untuk menerapkan pengendalian resiko terhadap unsur pengotor tersebut.

\section{METODE}

Metode yang digunakan pada pada penulisan artikel ini adalah observasi dan studi literatur dengan menggunakan bantuan search engine seperti google dan juga mengunjungi situs penyedia jurnal online Wiley dan NCBI. Literatur yang digunakan sebagai sumber data ilmiah 
adalah artikel dengan rentang tahun publikasi pada 2013 - 2016. Literatur hasil pencarian yang termasuk ke dalam inklusi adalah artikel dengan topik bahasan yang lebih spesifik mengenai penerapan ICH Q3D terhadap industri farmasi.

\section{HASIL}

Penerapan ICH Q3D pada negara anggota ICH dilakukan secara bertahap dan berkesinambungan yang dimulai dari produk baru lalu dilanjutkan pada produk yang telah beredar sebelumnya atau existing product.

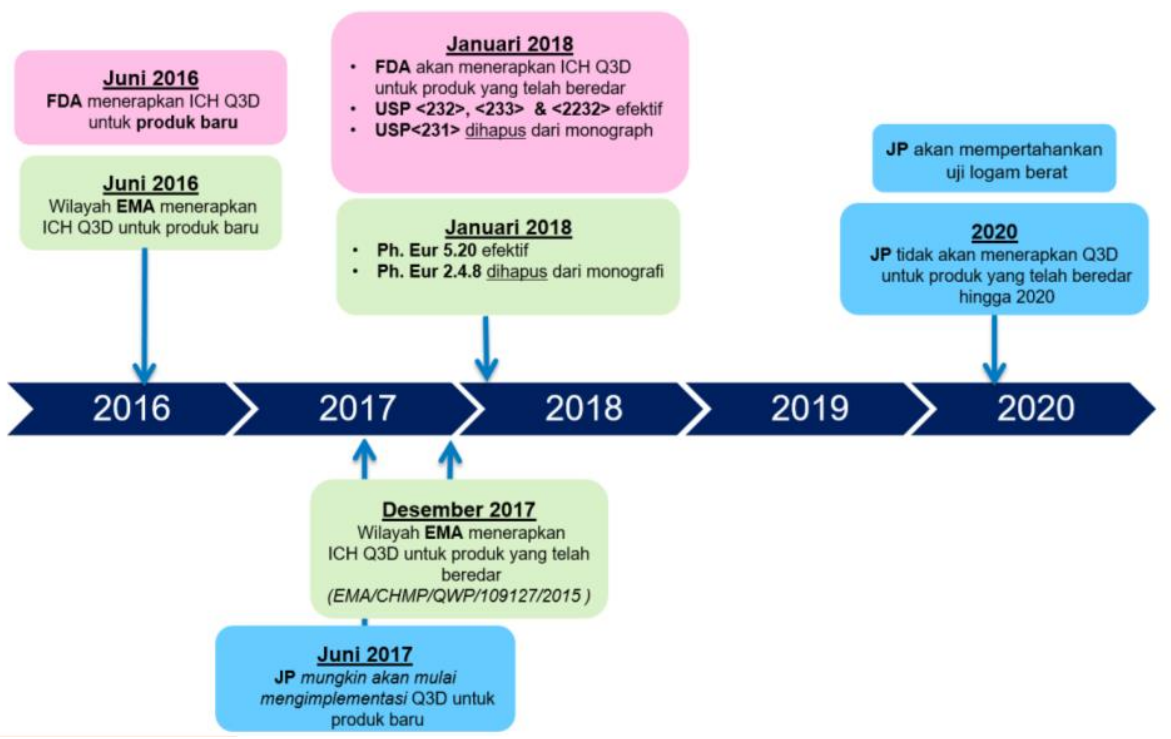

Gambar 1. Timeline Penerapan ICH Q3D pada negara anggota ICH 
Unsur dievaluasi melalui review data yang sudah ada sebelumnya seperti jurnal ilmiah, laporan hasil penelitian pemerintah, peraturan standar internasional, pedomannya, dan penelitian badan pengatur (regulator) dan laporan pengujiannya. Faktor - faktor yang perlu diperhatikan dalam pengujian keamanan untuk menentukan PDE (Permitted Daily Exposure) (ICH, 2014) :

- Kemungkinan adanya fase oksidasi dari unsur pada produk obat

- Paparan terhadap manusia dan data keamanannya

- Penelitian pada hewan yang paling berkaitan

- Rute pemberian

- Titik akhir yang berkaitan

Pada ICH Q3D sendiri sudah menunjukkan acuan PDE yang harus dipenuhi oleh industri farmasi dalam menguji unsur pengotor pada produk farmasinya.

Ketiadaan dari sebuah unsur pengotor dapat disimpulkan dengan bukti yang menunjukkan bahwa kadar unsur pengotor konsisten berada di bawah $30 \%$ dari PDE yang dihitung dan sesuai dengan rute pemberian produk farmasi tersebut berdasarkan asupan harian minimal 3 batch komersial atau 6 pilot batch dari produk akhir (EDQM, 2016).
The United States Pharmacopeial Convention (USP), bersamaan dengan the International Conference on Harmonisation (ICH), mengembangkan metode baru untuk pengotor anorganik pada produk obat dan bahan - bahannya yang nantinya digunakan dalam melakukan pengujian unsur pengotor sesuai dengan aturan ICH Q3D, metorde tersebut yakni General Chapter USP<232> (Limits) dan <233> (Procedures) dan dipublikasikan pada Desember 2015 (Liba, A., 2014).

Pengembangan metode baru dalam preparasi dan analisis dari sampel farmasi yang dijelaskan di ICH Q3D dan USP memberikan stimulasi laboratorium farmasi untuk memperbaharui metode serta instrument dalam menentukan pengujian kandungan unsur pengotor. USP merekomendasikan preparasi sampel, metode stabilisasi, dan metode analisis berdasarkan instrument ICP moderen seperti Inductively coupled plasma mass spectrometry (ICP-MS) dan inductively coupled plasma optical emission spectrometry (ICP-OES) (Liba, A. 2014).

Secara umum tedapat 2 (dua) strategi dalam menentukan unsur pengotor dalam produk obat pada proses preparasi sampel yakni, pelarutan dalam pelarut air atau pelarut organic dan ekstraksinya, wet digestion, dan combustion yang kemudian 
dilakukan pengujian menggunakan Inductively Coupled Plasma (ICP-OES atau ICP-MS), dan preparasi sampel menggunakan metode analisis sampel padat lalu diikuti dengan penggujian Electrothermal Vaporization (ETV), Laser Ablation (LA), dan Mass Spectrometry (MS). Penentuan unsur pengotor merupakan proses yang membutuhkan banyak pengembangan. Zat aktif yang digunakan pada produk obat memiliki cakupan yang luas dalam sifat fisik dan sifat kimia, sebagaimana dampak toksikologi terhadap manusia dan lingkungan, yang mengarah pada pengembangan dari pendekatan berbeda dalam pengujiannya. Hal tersebut membuat kinerja metode analisis (akurasi dan presisi) bukanlah satu-satunya parameter yang dipertimbangkan. Penerapan terhadap hasil pengujian, kemudahan penggunaan, dan biaya serta otomatisasi menjadi hal yang penting untuk dipertimbangakan, bahkan keselamatan dan kesehatan kerja turut tak terpisahkan dalam penentuan metode analisis yang akan digunakan (Barin, et al. 2016).

Harus ditekankan bahwa sampel kontrol kualitas seharusnya dianalisis bersama dengan sampel yang tidak diketahui sebagai sarana untuk memonitor kehadiran dan besaran kontaminasi.
Metode blanko harus dianalisis sebelum analisis sampel dengan pengotor yang belum diketahui. Peningkatan konsentrasi di atas Method Detection Limits (MDLs) dalam metode blanko menunjukkan kontaminasi selama persiapan sampel. Contoh yang harus ditentukan harus sesuai dengan jumlah yang diketahui analit sebelum preparasi sampel dan dievaluasi untuk tingkat peak recovery yang tinggi mungkin mengindikasikan kemungkinan kontaminasi dari persiapan sampel Timbal yang paling sering terkontaminasi oleh lingkungan dan laboratorium. Peak recovery untuk timbal bisa dikontrol di bawah $130 \%$ jika praktik lab bersih disarankan dalam penelitian untuk diikuti. Perlu dicatat metode blanko dan kontrol kualitas dengan matriks peak recovery sampel hanya memberikan gambaran kontaminasi dari persiapan sampel dan pengukuran sampel. Kontaminasi dari Sampel dan penyimpanan sampel harus dievaluasi secara hati-hati untuk integritas sampel dan kebersihan wadah sampel. Secara umum, studi yang dapat menunjukkan keberadaan pengotor selama pengujian diperlukan untuk mengevaluasi kebersihan selama proses pengujian sehingga mendapatkan data yang valid (Jin, C. 2016).

Dengan adanya keperluan penggunaan instrument baru dan 
persyaratan laboratorium lainnya, kebanyakan industri farmasi hanya memberikan sampel untuk diujikan kepada laboratorium pihak ketiga, hal ini dianggap lebih ekonomis dan efisien dibanding dengan melakukan investasi besar besaran dalam pemenuhan regulasi ICH Q3D

Pada awal tahap pengembangan produk, tidak disarankan untuk menyelidiki semua unsur pengotor. Investigasi mendalam biasanya tidak diperlukan untuk memastikan keamanan berkenaan dengan unsur pengotor selama uji klinis. Banyak perusahaan farmasi fokus terhadap kemungkinan pengotor dan pengotor yang paling mungkin terdapat selama fase pengembangan, padahal potensi pengotor dari jalur sintesis adalah zat antara, pelarut, dan reagen yang digunakan pada tahap akhir (Aslante, K. M., 2013).

Penilaian unsur pengotor pada packaging material turut menjadi hal yang krusial walaupun jumlahnya terbilang rendah dan tidak secara signifikan berkontribusi pada keberadaan unsur pengotor yang terdapat di produk obat, tetap perlu dilakukan penilaian resiko terutama pada material PET (Co), Multilaminate polyolefins $(\mathrm{Pb})$, dan $\mathrm{PVC}(\mathrm{Cd})$ untuk menguji PDEnya (Jenke, et al. 2015).

\section{PEMBAHASAN}

ICH Q3D sebagai regulasi yang mengatur unsur pengotor pada produk farmasi memiliki peranan penting dalam menjaga kualitas produk farmasi dari unsur - unsur pengotor yang tidak diperlukan. Hal ini akan meminimalisir keberadaan unsur pengotor tersebut. Walaupun unsur pengotor pada produk farmasi biasanya hanya dalam jumlah kecil, peraturan ini tetap perlu diterapkan untuk memastikan hal tersebut agar dapat dievaluasi dan didokumentasikan. Setiap proses yang dilalui dalam pembuatan produk farmasi berpotensi untuk terjadinya penambahan unsur pengotor selain unsur pengotor yang memang sudah terdapat dari bahan awal produk farmasi tersebut, baik peralatan hingga kemasan produk dapat memberikan unsur pengotor. Unsur pengotor yang terdapat pada produk farmasi berbentuk logam, keberadaan logam selalu dianggap ada kecuali dilakukan proses penghilangan unsur logam tersebut. Jumlah unsur pengotor yang ada pada produk farmasi tidak boleh melebih 30\% PDE sesuai dengan panduan ICH Q3D.

Industri farmasi yang akan menjual produknya di area yang dicakup oleh $\mathrm{ICH}$, yakni Eropa, Amerika Serikat, dan Jepang diwajibkan untuk pelaporan unsur 
pengotornya sesuai dengan tenggat waktu penerapan dari masing - masing negara tersebut. Beberapa negara peninjau-pun diperkirakan akan turut menerapkan peraturan ini. Selain menambah administrasi, ICH Q3D juga turut mempermudah regulasi pasar farmasi dunia, karena pihak industri cukup melakukan satu standar yang sama untuk pengujian dalam penyiapan pelaporan agar mendapatkan izin memasarkan produknya. Keberadaan ICH Q3D turut menjamin produk farmasi yang diperoleh oleh konsumen dapat terjaga kualitas, keamanan, dan khasiatnya dari unsur pengotor yang mungkin ada. Walaupun ada unsur pengotor, jumlahnya berada di batas aman untuk dikonsumsi.

Untuk menentukan jumlah unsur pengotor yang terbilang kecil membutuhkan alat deteksi yang memiliki Limit of Detection (LOD) yang rendah. LOD yang rendah akan meningkatkan keakuratan dari pendeteksiannya. Jika pada saat pengujian didapatkan nilai unsur pengotor yang melebihi batas 30\% PDE, maka perlu dilakukan evaluasi baik dalam bidang tahapan pembuatan, hingga penggantian kemasan. Dalam mendeteksi unsur pengotor ini industri farmasi perlu menginvestasikan dananya pada pengujian terutama instrument pengujian yang lebih moderen sehingga dapat memberikan efektifitas dalam penggujiannya dan investasi ini yang menjadi tantangan bagi industri farmasi karena tidaklah murah.

Pengontrolan jumlah unsur pengotor dapat dilakukan dengan berbagi strategi, contohnya pada spesifikasi komersil yang dipantau, pada pengendalian vendor dapat dilakukan revisi terhadap procurement specification, serta dapat dilakukan revisi terhadap produk akhir, atau prosesnya dengan cara menggunakan peralatan produksi alternatif maupun bahan pengemas alternatif dan reformulasi.

Selalu ada faktor potensial yang menyebabkan logam pengotor pada produk, yakni usia dan kondisi dari peralatan produksi, prosesnya, dan cara kerjanya. Pengotor logam itu harus diasumsikan terdapat pada produk kecuali dilakukan tahapan penghilangan. Unsur pengotor juga terdapat pada kemasan. Logam, plastik, dan kaca memiliki komposisi unsur pengotor yang mirip, namun kemasan logam dan kaca memiliki tingkat difusi yang lebih tinggi sehingga lebih berpotensial unsur pengotornya lepas dan mengkontaminasi produk, sedangkan plastik memiliki tingkat difusi yang rendah sehingga lebih kecil kemungkinannya untuk mengkontaminasi. Keberadaan chelating agents pada produk obat dapat membuat logam terpisah dari material 
kemasannya sehingga berpotensi mengkontaminasi.

\section{DAFTAR PUSTAKA}

Di Indonesia, Badan Pengawas Obat dan Makanan (BPOM) belum mensyaratkan penerapan ICH Q3D namun melihat tren regulasi yang dikeluarkan oleh BPOM seperti Cara Pembuatan Obat yang Baik (CPOB) merujuk peraturan pada ICH, maka ada kemungkinan bahwa di masa mendatang Indonesia akan menjadi salah satu negara yang menerapkan regulasi pengontrolan unsur pengotor dalam produk farmasi, terlebih lagi Indonesia saat ini berada pada posisi sebagai observer country terhadap ICH.

\section{KESIMPULAN}

Implementasi ICH Q3D bermanfaat untuk meningkatkan kualitas dari produk farmasi sehingga unsur pengotor yang terdapat pada produk farmasi dapat diminimalisir dan terdokumentasi dengan baik. Proses implementasi ICH Q3D pada industri farmasi akan membuat pihak industri melakukan investigasi akan kandungan unsur pengotor yang terdapat pada eksipien hingga finished good dengan mempertimbangan faktor - faktor yang ada pada proses pembuatan produk tersebut seperti peralatan dan kemasannya, disamping itu penerapan ICH Q3D akan turut meningkatkan kualitas dari produk farmasi itu sendiri.

Aslante, K. M., Huynh-Ba, Kim C., Baertschi, Steven W., Reed, Robert A., Landis, Margaret S., Furness, Scott., Olsen, Bernard., Mowery,Mark. Russo, Karen., Iser, Robert., Stephenson, Gregory A., and Jansen, Patrick. 2013. Recent Trends in Product Development and Regulatory Issues on Impurities in Active Pharmaceutical Ingredient (API) and Drug Products. Part 2: Safety Considerations of Impurities in Pharmaceutical Products and Surveying the Impurity Landscape. American Association of Pharmaceutical Scientists. 15(1).

Barin, Juliano S., Mello, Paola A., Mesko, Marcia F., Duarte, Fabio A., Erico M. M. 2016. Determination of elemental impurities in pharmaceutical products and related matrices by ICP-based methods: a review. Anal Bioanal Chem.

European Directorate for the Quality of Medicines \& Healthcare. 2016. Certification of suitability to the Monographs of the European Pharmacopoeia : Implementation of 
ICH Q3D in the Certification Procedure.

Food and Drug Administration. 2015. Q3D Elemental Impurities : Guidance for Industry.

Jenke, Dennis R., Stults, Cheryl L. M., Paskiet, Diane M., Ball, Douglas J., dan Nagao, Lee M. 2015. Materials in Manufacturing and Packaging Systems as Sources of Elemental Impurities in Packaged Drug Products: A Literature Review. PDA Journal of Pharmaceutical Science and Technology. 68. 1-48.

Jin, Chunguang. 2015. Clean Chemistry for Elemental Impurities Analysis of Pharmaceuticals in Compliance with USP 232. American Association of Pharmaceutical Scientists. 17(5).

Li, Gang., Schoneker, Dave., Ulman, Katherine L., Sturm, Jason J., Thackery, Lisa M., Kauffman, John F. 2015. Elemental Impurities in Pharmaceutical Excipients. Journal Of Pharmaceutical Sciences. 104:4197-4206.

Liba, A., dan Mccurdy, Ed. 2014. Proposed new USP general chapters
<232> and <233> for elemental impurities: The application of ICPMS for pharmaceutical analysis. Agilent Technologist USA.

The International Council for Harmonisation. 2014. ICH Harmonised Guidline : Guidline For Elemental Impurities Q3D. 